\title{
Desenvolvimento de um instrumento para a identificação de uma orientação construtivista no ensino de ciências
}

\author{
José Manuel do Carmoi \\ Universidade do Algarve, Portugal
}

Resumo

Embora o construtivismo possa ser considerado o paradigma dominante na educação em ciência, há, no entanto, uma deficiência quanto à disponibilidade de instrumentos para caracterizar a sua presença, tanto em pequenos grupos de professores num curso de formação contínua, como em larga escala para apreciar a orientação metodológica do ensino numa região ou país. Pela identificação de um conjunto de acontecimentos presentes no ensino comuns a diferentes orientações metodológicas, foi desenvolvido um instrumento para a explicitação pelos professores dos acontecimentos que integram uma sequência de ensino. Este instrumento permite a um formador, no início de um curso de formação, inicial ou contínua, uma apreciação expedita da metodologia praticada por um professor, possibilitando organizar a formação a partir do debate e reflexão sobre as conceções metodológicas dos participantes numa perspetiva construtivista da formação.

Palavras-chave

Ensino construtivista; Ensino de ciências; Estratégias de ensino; Perfil metodológico

\section{Introdução e enquadramento}

Desde as propostas iniciais, como as de Cosgrove e Osborne (1985), o construtivismo assumiu, no campo da educação em ciências, estatuto de tal 
modo generalizado que pode ser considerado atualmente o seu paradigma, situando-se o debate teórico amplamente no seu interior (Cachapuz, Praia, \& Jorge, 2002; Cachapuz, Praia, \& Jorge, 2004; Chakur, 2014; Mortimer, 1996; Praia, Cachapuz, \& Gil-Pérez, 2002; Sanchis \& Mahfoud, 2010; Thomson \& Gregory, 2013). O construtivismo poderá encontrar unidade em torno dos critérios seguintes: a) Identificar as ideias dos alunos; b) Criar oportunidades para os alunos explorarem as suas ideias e testar a sua solidez na explicação dos fenómenos, acontecimentos e previsões; c) Fornecer estímulos para os alunos desenvolverem e modificarem as suas ideias; d) Apoiar a reconstrução das suas ideias e pontos de vista (Hodson \& Hodson, 1998). Os professores deverão, assim, de um modo deliberado e estruturado, obter uma imagem clara do que os alunos já sabem e compreendem, de modo a poderem envolvê-los em atividades delineadas para que confrontem as suas ideias e os ajudem a recolher informação que lhes permita adquirir novos significados.

Todavia, embora constituindo um paradigma no campo da investigação educacional e no desenvolvimento curricular, em particular no domínio da educação em ciências, importa conhecer em que medida esta perspetiva se incorpora no conhecimento profissional dos professores e em que medida ela constitui património conceptual e está presente nas práticas de ensino de ciências.

A investigação da presença de características definidoras da ocorrência de um ensino com características construtivistas tem ocorrido principalmente em torno do estudo de casos de professores envolvidos em processos de formação e desenvolvimento profissional, a que se faz referência seguidamente.

A partir de observações de aulas e entrevistas com professores, Gallagher (1993) identificou seis tipos de conceções sobre o ensino de ciências como representações de estádios evolutivos de desenvolvimento profissional: 1. Ensino como transmissão do conteúdo científico: o papel do professor é a entrega do conhecimento pronto ao aluno; 2. Ensino como a organização do conteúdo científico: o professor como facilitador da assimilação do conteúdo pelos alunos; 3. Ensino como um conjunto estruturado de atividades manipulativas: o professor delineia atividades que permitem ao aluno descobrir os conceitos; 4. Ensino como um ciclo de 
aprendizagem: o professor propõe atividades que permitem observações exploratórias que favorecem a invenção de explicações e dão a oportunidade para a sua aplicação em outras situações; 5. Ensino como mudança conceptual: a partir da identificação das ideias dos alunos, o professor ajudaos a compreenderem as ideias científicas e facilita a sua integração no pensamento dos alunos; 6 . Ensino como um guia através de um processo construtivista: o professor ajuda os alunos a explicar as suas ideias próprias e cria situações em que as novas ideias ganham um significado ao se estabelecerem novas relações entre si. Destaque-se que as três primeiras categorias podem ser vistas como um gradiente do mais clássico modelo de ensino até um modelo mais evoluído de descoberta guiada. $\mathrm{O}$ autor considerou as três últimas como graus diferentes de um modelo de orientação construtivista.

Lam e Kember (2006), através de entrevistas a 18 professores do ensino artístico, estudaram a relação entre conceções de ensino e abordagens ao ensino. Os autores encontraram uma surpreendentemente clara relação entre uma prática centrada no aluno e na aprendizagem, associada a uma conceção de ensino dos professores centrada no desenvolvimento do aluno vs. uma prática de natureza transmissiva centrada no ensino e no professor em associação com uma conceção de ensino dos professores orientada para o conteúdo da disciplina.

So (2002), com base nas características de um ensino de natureza construtivista, desenvolveu um inventário de 22 itens, agrupados em 6 domínios, designadamente: 1. Usa o conhecimento prévio dos alunos para guiar o ensino; 2. Guia os alunos na geração de explicações e interpretações alternativas; 3. Delineia questões incisivas; 4. Escolhe materiais e atividades para os alunos testarem as suas ideias; 5 . Cria uma atmosfera de aula favorável à discussão; 6 . Fornece oportunidades para os alunos utilizarem as novas ideias. $O$ instrumento, aplicado por um observador das aulas de 25 alunos de um curso de formação inicial de professores do ensino primário, no âmbito de um módulo sobre ensino de ciências, permite a apreciação do tipo de ensino realizado, bem como a sua evolução ao longo de um processo de formação. A investigação mostra que apenas um número muito restrito (em torno dos $10-15 \%$ ) dos alunos-professores, após a inserção na prática docente, revela um ensino com características construtivistas. Os resultados 
permitem considerar que o instrumento revela sensibilidade para tornar evidentes posteriores avanços durante a imersão profissional destes alunosprofessores. A investigação permite ainda constatar a natureza conservadora do processo de formação, ao não introduzir grande impacto a adoção de uma lógica construtivista na bagagem profissional dos aluno-professores. Todavia, o instrumento, embora revelando uma imagem da prática existente num grupo de professores, apenas permite obter dados de uma amostra restrita e com uma exigência muito grande quanto à participação do investigador.

Com o propósito de encontrar uma metodologia que permita trabalhar com números elevados de professores, Porlán Ariza e colaboradores (Porlán Ariza, Rivero García, \& Martín del Pozo, 1998; Porlán Ariza \& Martín del Pozo, 2004) desenvolvem um modelo teórico cujas categorias são operacionalizadas relativamente aos domínios "imagem da ciência", "modelo de ensino", "elementos do currículo" e "teoria de aprendizagem". Relativamente a este último, definem três categorias, nomeadamente: "apropriação de significados", "assimilação de significados" e "construção de significados". Com base nestas subcategorias formulam um conjunto de itens que compõe um inventário (Inventory of Scientific Pedagogical Beliefs - ISPB) que permite aos autores referidos, através de uma análise multifatorial de componentes principais, identificar três fatores representando as diferentes dimensões das convicções dos professores da população considerada relativamente ao domínio "teoria de aprendizagem" subjacente. Um fator, explicando cerca de $21 \%$ da variância, revela uma visão da aprendizagem integrando itens do inventário da categoria "apropriação de significados". Um fator, correspondendo a cerca de $15 \%$ da variância, integra itens do inventário considerados essencialmente na categoria "assimilação de significados". Cerca de $9 \%$ da variância são explicados por itens do inventário considerados na categoria "construção de significados". Poderemos deste modo considerar que apenas cerca de $10 \%$ dos professores da amostra considerada revelam traços pertinentes a uma metodologia de orientação construtivista. Martin e colaboradores (2014) procuram identificar as teorias implícitas dos professores, pela resposta que selecionam numa série de dilemas. As respostas que os autores propõem aos professores correspondem a representações concretas dos três modelos teóricos na docência que consideram: Direto, Interpretativo e Construtivo. Os autores encontram um 
perfil de professores correspondendo a $42 \%$ que se identificam maioritariamente com as respostas pertinentes a convicções teóricas do modelo teórico "interpretativo" e poucas do modelo teórico "direto"; um outro perfil, correspondendo a $38 \%$, selecionam essencialmente respostas enquadráveis no modelo teórico "construtivo" com muito poucas respostas nos restantes dois modelos, e finalmente um perfil correspondendo a $20 \%$ da amostra que se identifica com respostas pertinentes às convicções teóricas "diretas" e "interpretativas". Estes estudos procuram caracterizar/identificar as conceções sobre ensino presentes numa população de professores assumindo uma correspondência com as teorias em uso na organização da prática docente.

Kabapinar (2010) pediu a futuros professores que explicassem num desenho/caricatura a visão construtivista do ensino e da aprendizagem e, ainda, que a explicitassem por escrito do modo mais detalhado que pudessem. Os desenhos dos futuros professores turcos referem na sua quase totalidade (91.6\%) aspetos pertinentes à teoria construtivista e, na explicitação escrita, referem aspetos característicos da conceção construtivista do ensino e da aprendizagem. Isto é, os professores têm o conhecimento, mas muito seguramente este valor está longe do que realmente se poderá encontrar na prática de ensino.

O estudo da OCDE "Criar Ambientes de Ensino e Aprendizagem Eficientes" (OECD, 2009) mostra que, embora na generalidade dos países os professores na sua maioria optam por se identificar com convicções correspondendo a uma "visão construtivista", quando caracterizam a sua prática, referem principalmente elementos ou acontecimentos pedagógicos pertinentes a uma prática de tipo "estruturante" (Structuring practices) face a práticas "orientadas ao aluno" (Student-oriented practices) e ainda menos orientadas para o desenvolvimento de níveis elevados de pensamento (Enhanced activities). Isto é, a utilização de instrumentos que caracterizam as conceções ou crenças apenas permite identificar o discurso, por vezes já adaptado à teoria da prática, do mesmo modo que os alunos frequentemente adaptam o discurso da escola às suas conceções científicas pessoais.

Oliva, Azcárate e Navarrete (2007), interessados em estudar os modelos de ensino na utilização de analogias e situando-se no quadro de um paradigma construtivista, procuram identificar os modelos de ensino dos 
professores recorrendo a apenas dois parâmetros: atividade do aluno e papel regulador (monitoring) do professor. Com base nestes dois parâmetros, estes autores geram um conjunto de descritores do modo de seleção, apresentação e exploração de analogias no ensino, organizadas segundo uma matriz de quatro modelos gerais de ensino:

- Enfoque tradicional - Apresentação de analogias pré-fabricadas e sua explicitação pelo professor. Baixa atividade dos alunos e baixo papel regulador do professor;

- Modelo tecnológico de transmissão significativa. Apresentação de analogias pré-fabricadas e tarefas estruturadas facilitadoras da assimilação dos significados. Baixa atividade dos alunos e elevado papel regulador do professor;

- Modelo espontâneo, auto-descoberta - Analogias pessoais autoelaboradas sem orientação. Alta atividade dos alunos e baixo papel regulador do professor;

- Enfoque sócio-construtivista - Intervenção através de tarefas estruturadas levando à construção de analogias pela negociação de significados na interação professor-aluno.

A investigação de Oliva et al. (2007), prescindindo da observação direta das ocorrências na sala de aula, permite captar a identificação dos professores com descritores da prática e caracterizar as suas orientações metodológicas. Utilizando apenas dois parâmetros, papel regulador do professor e atividade do aluno, estes autores identificam quatro padrões de prática, em que apenas $11 \%$ correspondem a um ensino com características construtivistas (Oliva et al., 2007).

Note-se a coincidência dos vários estudos referidos atrás (Lam \& Kember, 2006; Oliva et al., 2007; Porlán Ariza et al., 1998; Porlán Ariza \& Martín del Pozo, 2004; So, 2002), com as categorias ou perfis metodológicos propostos inicialmente por Gallagher (1993). Pode salientar-se também a ideia de que um ensino focado no conteúdo se relaciona com uma visão transmissiva do ensino, enquanto uma perspetiva do professor como facilitador da aprendizagem estará associada a uma ênfase em atividades centradas nos alunos (Lam \& Kember, 2006).

O objetivo deste trabalho é o de desenvolver um instrumento capaz de caracterizar a metodologia aplicada na sala de aula, sem a presença de um 
observador. Na preparação de uma qualquer ação de formação ou curso, em particular focada na metodologia e ensino de ciências, abrangendo até duas dezenas de participantes e orientada por apenas um ou dois formadores, a adoção de uma metodologia de formação de natureza construtivista exigirá o desenvolvimento de um instrumento que, de um modo expedito, possibilite não só o conhecimento prévio da estrutura metodológica dos formandos e apreciar a sua evolução, como também facilite o processo formativo, nomeadamente pela possibilidade de ser respondido em ambiente de formação e possa ser analisado de uma sessão a outra de curso ou ação de formação, permitindo o debate e a argumentação sobre as opções tomadas.

Parte-se do pressuposto de que os acontecimentos pedagógicos da sala de aula, quando definidos com um adequado grau de generalidade, são comuns a diversas organizações do ensino, sendo apenas característicos de uma metodologia construtivista os momentos em que se inserem na sequência pedagógica. $O$ fornecimento de informação pelo professor, a explicitação dos conceitos pelos alunos, o contacto com situações concretas que os alunos exploram e com as quais confrontam o seu conhecimento são exemplos de acontecimentos pedagógicos que ocorrerão muito vulgarmente, e apenas o momento em que ocorrem na organização do ensino faz a diferença quanto à metodologia utilizada. Numa perspetiva construtivista, o contacto com situações concretas que os alunos exploram assumirá uma função de estimulação do desequilíbrio cognitivo pelo desafio dos conhecimentos prévios, situando-se no início de uma estratégia de ensino. Numa perspetiva clássica, transmissiva, este contacto poderá ter a função de ilustração ou verificação dos conhecimentos fornecidos pelo ensino, situandose assim no final de uma sequência estratégica, ou no seu início, se for seguida pela explicação do fenómeno pelo professor.

Partindo deste pressuposto, num primeiro momento deste estudo, procurou identificar-se um conjunto de aspetos, acontecimentos pedagógicos que se prefigurem como invariantes, isto é, redigidos de uma forma suficientemente ampla de modo a constituírem elementos comuns a sequências de ensino com diferentes orientações metodológicas. Os descritores destes "acontecimentos pedagógicos" deverão poder ser percecionados pelos professores como fazendo parte da sua prática e deverão poder ser por eles ordenados de modo a traduzirem a representação 
da sua "sequência pedagógica" pessoal, isto é, produzirem um perfil metodológico individual. Neste estudo pretende-se apreciar a capacidade deste conjunto de invariantes para caracterizar as metodologias utilizadas pelos professores.

\section{Método}

\section{Construção de um inventário de acontecimentos pedagógicos}

Procurou-se, num primeiro momento, a definição de um conjunto de aspetos ou acontecimentos pedagógicos que se prefigurem como invariantes, isto é, redigidos de uma forma suficientemente ampla de modo a constituírem elementos comuns, independentemente da estrutura metodológica subjacente à organização do ensino; apenas a ordem em que aparecem nessa sequência Ihes atribui claro significado pedagógico. Num estudo exploratório com um número muito limitado de professores (2), de que eram conhecidos os estilos de organização do ensino, através de entrevistas e por observação direta repetida de aulas, foi possível elaborar uma lista de frases descrevendo acontecimentos pedagógicos (fig. 1). Da lista de sete frases, três correspondem a acontecimentos pedagógicos centrados no professor (A, E e $\mathrm{G}$ ) e outros três a acontecimentos pedagógicos centrados nos alunos (C, D e F). A frase B (Os alunos têm oportunidade de contactar com situações ou acontecimentos relativos ao assunto) tanto pode corresponder a uma oportunidade para exploração pelo aluno, a partir da qual se inicia um ciclo de construção do conhecimento, ou a uma contextualização necessária para que o professor explique a matéria; também pode representar um momento de ilustração ou de aplicação de conhecimentos anteriormente ensinados pelo professor.

Enquanto numa estratégia de ensino "clássica" se esperaria uma sequência inicial de acontecimentos pedagógicos centrados no professor, numa sequência de tipo construtivista estes deveriam revelar acontecimentos centrados na relação concreta dos alunos com a situação.

A - Pelo diálogo ou exposição apresentam-se alguns factos ou aspetos relativos ao assunto.

B - Os alunos têm oportunidade de contactar com situações ou acontecimentos relativos ao assunto. 
C - Os alunos expuseram pelo diálogo, ou de outro modo, o que entendiam do tema ou assunto.

D - Listou-se um conjunto de questões ou interesses a partir dos quais se organizou a sequência das aprendizagens.

E - Os conteúdos foram ensinados numa sequência ditada pela lógica das relações entre si, de um modo muito próximo de como a matéria é estruturada no livro adotado.

F - Os alunos aprendem em grande parte pelo recurso a fontes diversificadas de informação.

G - O professor introduziu exemplos de situações da vida quotidiana relativas aos conceitos envolvidos.

Figura 1 - Acontecimentos pedagógicos invariantes presentes no ensino

$A$ - Pelo diálogo ou exposição apresentam-se alguns factos ou aspetos relativos ao assunto.

$B$ - Os alunos têm oportunidade de contactar com situações ou acontecimentos relativos ao assunto.

C - Os alunos expuseram pelo diálogo, ou de outro modo, o que entendiam do tema ou assunto.

$D$ - Listou-se um conjunto de questões ou interesses a partir dos quais se organizou a sequência das aprendizagens.

$E$ - Os conteúdos foram ensinados numa sequência ditada pela lógica das relações entre si, de um modo muito próximo de como a matéria é estruturada no livro adotado.

$F$ - Os alunos aprendem em grande parte pelo recurso a fontes diversificadas de informação.

G - O professor introduziu exemplos de situações da vida quotidiana relativas aos conceitos envolvidos.

Delineou-se um instrumento, que designaremos "Sequência Pedagógica", no qual se apresenta a lista de acontecimentos pedagógicos da figura $1 \mathrm{e}$ em relação à qual se solicita aos respondentes que: 1) identifiquem os acontecimentos presentes no seu ensino relativamente à última unidade didática lecionada, e 2) ordenem esses acontecimentos pela sequência em que ocorreram no seu ensino. Deste modo, gerar-se-á para cada sujeito uma "Sequência Pedagógica" correspondente ao modo como perceciona a organização da sua prática (ver anexo 1).

\section{Metodologia de validação do instrumento}

No sentido de validar este instrumento, procurou verificar-se a coerência entre as "Sequências Pedagógicas" produzidas e outro tipo de informação sobre as práticas dos professores. 
Em primeiro lugar, selecionaram-se, para colaborar na aplicação deste instrumento, oito professores de que se conhecia o estilo de prática, por colaboração direta com o investigador na tutoria e acompanhamento da iniciação à prática letiva de alunos-professores. Destes, em quatro esperavase a presença de sequências de ensino mais centradas no aluno e na aprendizagem, revelando uma tendência no sentido de uma metodologia construtivista (grupo "construtivista"); nos outros quatro havia a expectativa de uma prática centrada no professor e no seu ensino, típica do que é mais correntemente praticado nas nossas escolas (grupo "transmissivo"), pelo que se esperavam sequências de ensino compostas por acontecimentos pedagógicos centrados no professor.

Em segundo lugar, uma estratégia de organização de ensino de carácter construtivista deverá dar ênfase a atividades promovendo os processos de pensamento. A utilização de um instrumento como o "Laboratory Assessment Inventory", de Tamir e Pilar-Garcia (1992), que procura quantificar a presença de atividades letivas para o ensino dos processos de pensamento científico, deverá revelar valores mais elevados para os professores que indicaram sequências características de práticas mais centradas na atividade do aluno. $\mathrm{O}$ instrumento descrito por Tamir e PilarGarcia (1992) inclui uma lista (22 itens) descrevendo comportamentos específicos organizados em quatro subcategorias (planeamento, desempenho, análise e aplicação), tendo revelado capacidade para ser aplicado em situações diversas, nomeadamente, na análise de manuais escolares no trabalho citado. Este instrumento foi adaptado para a apreciação dos professores quanto à frequência da ocorrência (uma, duas, três, ou mais vezes) de cada um dos itens do inventário na mais recente unidade de ensino lecionada (ver anexo 2).

Em terceiro lugar, uma estratégia de ensino centrada nos alunos, ou centrada no professor, deverá dar origem a diferentes perceções dos alunos quanto à relevância para a sua aprendizagem, de determinados tipos de situações pedagógicas, reveladora da ênfase que Ihes foi dada: estratégias de ensino tendentes a uma metodologia apresentando características construtivistas induzirão nos alunos uma perceção sobre o modo como aprendem ciências diferente de outro grupo que aplica um ensino mais tradicional. Foi construído um inventário de situações pedagógicas, 
características da sala de aula ou de possíveis oportunidades para aprender no exterior da escola. Este instrumento - "Perceção pelos alunos do ensino praticado" -, com um formato Likert, foi estruturado de modo a poder ser apresentado aos alunos com o pedido de apreciarem o modo como aprendem ciências (Muito, alguma coisa, pouco ou nada, a que se atribuem os valores $3,2,1,0)$. Centrado na perceção dos alunos acerca do grau de presença de comportamentos letivos na sua aprendizagem, procura obter dados sobre a prática, na perspetiva dos alunos (anexo 3).

\section{Procedimento}

Os instrumentos para a caracterização metodológica - "Sequência Pedagógica" (anexo 1) - e para a apreciação da ocorrência de "Processos de Pensamento Científico" (anexo 2) no ensino foram aplicados aos oito professores referidos que constituem a amostra. Aos participantes foi inicialmente pedida a resposta aos instrumentos referidos, apenas se thes explicando que se tratava de uma experiência de verificação da sua utilidade como caracterizadores do ensino. Seguidamente, solicitou-se a explicitação da sequência apresentada de modo a confirmar a leitura que o investigador poderia fazer da sequência selecionada. Deste modo, foi possível constatar que um dos elementos (professor d), à partida selecionado como integrante do grupo "construtivista" revelou, encontrar-se numa situação que considerava especial e, por esse motivo, estaria a implementar um ensino muito tradicional, que Ihe era incaracterístico. Este sujeito passou assim a ser considerado do grupo "transmissivo".

Após esta aplicação, foi solicitado aos professores que aplicassem aos alunos de uma das turmas o instrumento para identificação da "Perceção pelos alunos do ensino praticado" (anexo 3). O número de alunos inquiridos foi de 78 para o grupo "construtivista" (professores a, b e c) de 81 para o grupo "transmissivo" (professores d, e, f, g e h).

\section{Resultados}

As sequências de acontecimentos pedagógicos indicadas por cada um dos professores inquiridos estão registadas na tabela 1. As sequências mostram que os professores do grupo "construtivista", ao contrário dos do 
grupo "transmissivo", tendem a iniciar a organização do seu ensino com acontecimentos centrados nos alunos e só após recorrem ao ensino centrado no professor.

\begin{tabular}{|c|c|c|c|c|c|}
\hline \multirow{2}{*}{ A - } & \multirow{2}{*}{$\begin{array}{l}\text { B - Sequência pedagógica } \\
\text { (ver figura 1) }\end{array}$} & \multicolumn{4}{|c|}{ C - Processos de pensamento científico } \\
\hline & & Planeamento & Desempenho & Análise & Aplicação \\
\hline \multicolumn{6}{|c|}{ Grupo "construtivista" } \\
\hline a & $\underline{D C B A F G E}^{*}$ & 2,8 & 2,6 & 3 & 2,8 \\
\hline b & DCBFGA & 3 & 2,6 & 2,3 & 2,3 \\
\hline \multirow[t]{2}{*}{ c } & DCGAF & 3 & 2,6 & 3 & 2,3 \\
\hline & Média & 2,9 & 2,6 & 2,8 & 2,5 \\
\hline
\end{tabular}

Grupo "transmissivo"

\begin{tabular}{|c|c|c|c|c|c|}
\hline$d$ & DABCGEF & 2,8 & 2 & 2 & 1,5 \\
\hline e & $\underline{A G B E}$ & 0,8 & 1,3 & 1,7 & 1,5 \\
\hline$f$ & EGABF & 2 & 2,1 & 0,5 & 3 \\
\hline g & AGEBC & 2 & 2 & 2 & 2,2 \\
\hline \multirow[t]{2}{*}{$\mathrm{h}$} & $\underline{\text { EAGDBF }}$ & 1,4 & 2 & 1 & 2 \\
\hline & Média & 1,8 & 1,9 & 1,4 & 2,0 \\
\hline
\end{tabular}

Para cada um dos sujeitos do estudo (coluna A), comparação entre a sequência pedagógica (coluna B) e as médias obtidas para cada uma das subescalas do instrumento "Processos de Pensamento Científico"(coluna $\mathrm{C}$ ).

*As letras correspondem aos "acontecimentos pedagógicos" descritos na figura 1.

Tabela 1 - Sequência pedagógica e perceção da utilização de Processos de Pensamento Científico no ensino

Na tabela 1 pode ver-se como a autoapreciação do peso da presença de processos de pensamento científico no ensino é maior nas quatro subcategorias do instrumento nos professores do grupo "construtivista", de modo coerente com a expectativa hipotética (coluna C - Processos de pensamento científico). Os professores deste grupo afirmam iniciar um ciclo pedagógico por uma sequência de dois itens:

D - Listou-se um conjunto de questões ou interesses a partir dos quais se organizou a sequência das aprendizagens.

C - Os alunos expuseram pelo diálogo, ou de outro modo, o que entendiam do tema ou assunto. 
Segue-se um momento considerado de contacto dos alunos com situações concretas, nas quais as suas ideias são confrontadas:

B - Os alunos têm oportunidade de contactar com situações ou acontecimentos relativos ao assunto.

G - O professor introduziu exemplos e situações da vida quotidiana relativas aos conceitos envolvidos.

Só então poderá surgir um momento de aprendizagem formal, eventualmente centrada no professor.

Pelo contrário, no grupo "transmissivo" o início de um ciclo pedagógico é dominado pela apresentação de matéria (itens $\mathrm{A}$ e E), articulada com exemplos concretos (item $\mathrm{G}$ ):

A - Pelo diálogo ou exposição apresentam-se alguns factos ou aspetos relativos ao assunto.

E - Os conteúdos foram ensinados numa sequência ditada pela lógica das relações entre si, de um modo muito próximo de como a matéria é estruturada no livro adotado.

G - O professor introduziu exemplos e situações da vida quotidiana relativas aos conceitos envolvidos

É de notar que o professor d, inicialmente selecionado para integrar o grupo "construtivista", mas que declarou estar a seguir uma metodologia "clássica" que the era atípica, revela precisamente esse padrão.

$\mathrm{Na}$ tabela 2 apresentam-se os resultados obtidos em cada um dos itens do instrumento "Perceção pelos alunos do ensino praticado" (anexo 3) para os alunos dos professores do grupo "construtivista" (coluna A) e do grupo "transmissivo" (coluna B). Estes dois grupos diferem (de modo estatisticamente significativo com a utilização do teste $T$ de Student) na perceção da ênfase de um certo número de parâmetros pedagógicos no modo como aprendem ciências. Na coluna $T$ test indica-se a probabilidade calculada de que as populações difiram significativamente. A indicação do desvio padrão (colunas $\mathrm{dp}$ ) permite apreciar a dispersão de resultados para cada item e grupo. Os alunos do grupo "construtivista" sentem mais do que os do grupo "transmissivo" o contributo da apresentação do professor, das experiências que os alunos efetuam e do trabalho em grupo com os colegas. Demonstrações feitas pelo professor e a necessidade de recorrer a outros são mais sentidas pelos alunos do grupo "transmissivo". 


\begin{tabular}{|c|c|c|c|c|c|}
\hline \multirow{2}{*}{$\begin{array}{l}\text { O contributo que teve para a minha aprendizagem } \\
\text { Aspeto inquirido }\end{array}$} & T test & \multicolumn{2}{|c|}{ A-grupo } & \multicolumn{2}{|c|}{ B-grupo } \\
\hline & $p=$ & Média & $d p$ & Média & d.p. \\
\hline Explicação do professor & .047 & 2,78 & 0,05 & 2,63 & 0,54 \\
\hline Diálogo entre professor e alunos & .229 & 2,64 & 0,64 & 2,52 & 0,64 \\
\hline Experiências que fizeste com os colegas & $.0001^{\star \star \star}$ & 2,36 & 0,70 & 1,53 & 0,79 \\
\hline Experiências que vi o professor fazer &, $006 \quad * *$ & 1,61 & 1,13 & 2,04 & 0,78 \\
\hline Visitas de estudo e outras extra aula & .17 & 1,54 & 0,75 & 1,35 & 0,98 \\
\hline Perguntas que o professor fez & .16 & 2,76 & 0,46 & 2,64 & 0,58 \\
\hline Conversas com outras pessoas & .030 & 1,47 & 0,91 & 1,79 & 0,90 \\
\hline O livro de ciências & .68 & 2,56 & 0,68 & 2,60 & 0,58 \\
\hline Outros livros que li & .48 & 1,65 & 0,91 & 1,75 & 0,93 \\
\hline Fichas de trabalho do professor & .28 & 2,22 & 0,77 & 2,35 & 0,71 \\
\hline Filmes, fotografias ou slides que vi na aula & .32 & 1,45 & 1,03 & 1,60 & 0,97 \\
\hline Programas de televisão que vi & .30 & 1,90 & 0,98 & 1,72 & 1,20 \\
\hline Trabalho de grupo com os outros colegas & $.0001^{\star \star \star}$ & 2,56 & 0,66 & 1,99 & 0,78 \\
\hline
\end{tabular}

Tabela 2 - Comparação na perceção do modo como melhor aprendem ciências entre os alunos dos dois grupos

\section{Discussão dos resultados e conclusão}

Embora este trabalho não permita apreciações quantitativas, os dados provenientes das investigações referidas anteriormente mostram que os instrumentos que procuram apreciar o ensino a partir das conceções e conhecimento pedagógico dos professores podem estar muito longe da realidade da prática efetivamente existente. Como Marzábal, Rocha e Toledo (2015), consideramos importante que, na elaboração de uma proposta de formação contínua de professores tendo como propósito promover a apropriação de um modelo didático proposto, possa iniciar-se com a identificação das representações implícitas dos professores participantes de modo a confrontá-los com as características da prática propostas pelo novo modelo, a partir das suas características concetuais e fundamentos teóricos. Estes autores propõem uma metodologia baseada na autoanálise dos participantes sobre vídeo gravações das suas aulas com base num conjunto de critérios; todavia, este procedimento, tal como a metodologia para caracterização do ensino centrada na observação de aulas, anteriormente referida (So, 2002), é demasiado exigente em termos técnicos e humanos e, portanto, pouco exequível. Mais do que observar uma aula, ou observar toda 
uma unidade de ensino, a indicação, por um professor, de uma sequência de ensino que traduza a sua melhor prática, poderá permitir o debate formativo em torno das conceções metodológicas num grupo de professores. As sequências pedagógicas obtidas parecem mostrar padrões de estrutura metodológica entre os dois grupos considerados, coincidentes com o pressuposto inicial do investigador quanto à diferença de estilos metodológicos que determinou a escolha dos sujeitos.

Os sujeitos incluídos no grupo "construtivista" apresentam, de facto, características coerentes com a designação adotada por iniciarem o seu ciclo de aprendizagem por uma sequência centrada nas questões e conhecimentos dos alunos, a que se segue um momento de confronto das ideias dos alunos com situações concretas, previamente à introdução de um ensino formal, afastando-se deste modo de uma perspetiva clássica de início do processo de ensino pela explicação do professor. Os resultados evidenciam ainda a possível existência de um padrão de que está ausente um momento inicial de manipulação ativa, a partir do qual se projetariam os conhecimentos prévios dos alunos e surgiriam as questões que levariam a uma reconceptualização ou reestruturação do conhecimento formal.

Para as duas categorias consideradas, também os alunos mostraram percecionar uma diferença em relação a cinco parâmetros do instrumento "Perceção pelos alunos do ensino praticado" (tabela 2 e anexo 3). A atividade experimental e o trabalho em grupo com os colegas são elementos da aprendizagem que mostram a maior diferença entre os dois grupos. De modo coerente, há também uma diferença de perceção a respeito do impacto das demonstrações feitas pelo professor, que são mais notadas pelos alunos ensinado por professores do grupo "transmissivo". Será interessante notar que a apresentação da matéria pelo professor acaba por ser mais bemsucedida no grupo "construtivista". A resposta dos alunos pode não significar que estes professores expliquem durante mais tempo, mas apenas que o fazem com mais sucesso, o que aliás se revela coerente com a perceção dos alunos do grupo "transmissivo" de que recorrem mais a "outros" para aprender ciências.

Poderá assim considerar-se que o instrumento "Sequência Pedagógica" para caracterização metodológica da prática parece servir os fins a que se destina, isto é, distinguir, na ausência de um observador, 
padrões de prática mais centrados nos alunos, segundo um modelo construtivista, de padrões de prática mais centrados no professor, seguindo um modelo clássico de transmissão. A apresentação aos professores de um conjunto de acontecimentos pedagógicos e a sua ordenação como uma sequência permite identificar a conceção metodológica subjacente à sua organização do ensino. O instrumento poderá ter uma utilidade grande do ponto de vista formativo por permitir a adoção de uma perspetiva construtivista na própria formação, ao tornar possível iniciar um curso de formação pela explicitação das conceções metodológicas dos participantes e permitir o seu debate e a fundamentação das escolhas efetuadas à luz dos resultados da investigação, bem como apreciar a sua reelaboração na sequência de um processo formativo.

$\mathrm{Na}$ continuação desta, uma outra investigação procura, através de entrevistas aos participantes, uma melhor compreensão do significado dado e do pensamento subjacente às escolhas feitas pelos professores, tanto na seleção dos "acontecimentos pedagógicos" presentes no seu ensino como da "sequência pedagógicas" em que se inserem, levando a um aprofundamento da validação deste instrumento. A aplicação a um grupo mais alargado de professores permitirá apreciar a capacidade para discriminar modelos ou tipologias de prática.

\section{Referências}

Cachapuz, A., Praia, A., \& Jorge, M. 2002. Ciência, educação em ciência e ensino das ciências. Lisboa: Ministério da Educação.

Cachapuz, A., Praia, A., \& Jorge, M. (2004). Da educação em ciência às orientações para o ensino das ciências: Um repensar epistemológico. Ciência \& Educação, 10(3), 363-381.

Chakur, C.R.S.L. (2014). A desconstrução do construtivismo na educação: Crenças e equívocos de professores, autores e críticos. S. Paulo: UNESP.

Cosgrove, M., \& Osborne, R. (1985). Lesson frameworks for changing children's ideas. In R. Osborne, \& P. Freyberg (Eds.), Learning in science: The implications of children's science. Auckland: Heinemann.

Gallagher, J. J. (1993). Six views of teaching science: An invitation to reflection and discussion. East Lansing: Michigan State University, College of Education, National Center for Research on Teacher Learning. 
Hodson, D., \& Hodson, J. (1998). From constructivism to social constructivism: A vygotskian perspective on teaching and learning science. School Science Review, 79(2), 33-41.

Kabapinar, Y. (2010) Turkish prospective teachers' images of the constructivist view of teaching: are they compatible with the epistemological foundations of constructivism?. Procedia Social and Behavioral Sciences, 2(2) 1223-1228. Disponível em: www.sciencedirect.com

Lam, B. H., \& Kember, D. (2006). The relationship between conceptions of teaching and approaches to teaching. Teachers and Teaching: Theory and Practice, 12(6), 693-713.

Martin, E., Pozo, J. I., Mateos, M., Martin, A., \& Echeverría, M. P. P. (2014). Infant, primary and secondary teachers' conceptions of learning and teaching and their relation to educational variables. Rev Latinoam Psicol., 46(3), 211 -221.

Marzábal, A., Rocha, A., \& Toledo, B. (2015). Caracterización del desarrollo profesional de profesores de ciencias - parte 2: Proceso de apropiación de un modelo didáctico basado en el ciclo constructivista del aprendizaje. Educación Química, 26, 212-223

Mortimer, E. F. (1996). Construtivismo, mudança conceitual e ensino de ciências: Para onde vamos? Investigações em Ensino de Ciências, 1(1), 20-39.

OECD (2009). Creating Effective Teaching and Learning Environments. First Results from TALIS (Teaching and Learning International Survey). https://www.oecd.org/edu/school/43023606.pdf

Oliva, J. M., Azcárate, P., \& Navarrete, A. (2007). Teaching models in the use of analogies as a resource in the science classroom. International Journal of Science Education, 29(1), 45-66.

Porlán Ariza, R., \& Martín del Pozo, R. (2004). The conceptions of in-service and prospective primary school teachers about the teaching and learning of science. Journal of Science Teacher Education, 15(1), 39-62.

Porlán Ariza, R., Rivero García, A., \& Martín del Pozo, R. (1998). Conocimiento profesional y epistemología de los profesores, II: Estudios empíricos y conclusiones. Enseñanza de las Ciencias, 16(2), 271-288.

Praia, J. F., Cachapuz, A. F. C., \& Gil-Pérez, D. (2002). Problema, teoria e observação em Ciência: Para uma reorientação epistemológica da educação em ciência. Ciência \& Educação, 8(1), 127-145.

Sanchis, I. P., \& Mahfoud, M. (2010). Construtivismo: Desdobramentos teóricos e no campo da educação. Revista Eletrônica de Educação, 4(1), 18-33. http://www.reveduc.ufscar.br

So, W. W. M. (2002). Constructivist teaching in primary science. Asia-Pacific Forum on Science Learning and Teaching, 3(1), article 1. https://www.ied.edu.hk/apfslt/

Tamir, P., \& Pilar-Garcia, M. (1992). Characteristics of laboratory exercises included in science textbooks in Catalonia (Spain). Science Education, 14(4), 381-392.

Thomson, M. M., \& Gregory, B. (2013). Elementary teachers' classroom practices and beliefs in relation to US science education reform: Reflections from within. International Journal of Science Education, 35(11), 1800-1823. 


\title{
DEVELOPMENT OF AN INSTRUMENT FOR IDENTIFICATION OF A CONSTRUCTIVIST ORIENTATION IN SCIENCE TEACHING
}

\begin{abstract}
Even if constructivism might be considered the main paradigm in science education, there is, however, a deficient availability in regard to instruments to characterize its presence, either in a small group of teachers in an in-service training course, or in a large sample of teachers giving a view of the methodological orientation of teaching in a region or country. By identifying a set of events that are present in teaching and are common to different methodological orientations, an instrument was developed to elicit teachers' sequence of events in the beginning of a teaching sequence. It allows a teacher trainer, at the beginning of an in-service or initial training course, a fast and prompt assessment of teachers' methodology in practice, making it possible to organize the training course starting from a debate and reflection over participant teacher's methodological conceptions in a constructivist perspective of teacher training.
\end{abstract}

Keywords

Constructivist teaching; Science teaching; Teaching strategies; Teaching profile

\section{ELABORACIÓN DE UN INSTRUMENTO PARA LA IDENTIFICACIÓN DE UNA ORIENTACIÓN CONSTRUCTIVISTA EN LA ENSEÑANZA DE CIENCIAS}

\section{Resumen}

Aunque el Constructivismo pueda ser considerado el paradigma dominante en la educación en ciencia, hay, todavía, una deficiencia cuanto a la disponibilidad de instrumentos para cuantificar su presencia, tanto en pequeños grupos de profesores en un curso de superación, como en una escala amplia para apreciar la orientación metodológica de la enseñanza en 
una región o país. La identificación de un conjunto de acontecimientos presentes en la enseñanza comunes a diferentes orientaciones metodológicas ha permitido el desarrollo de un instrumento para la explicitación de los acontecimientos presentes en una secuencia de enseñanza, permitiendo a un formador, en el inicio de un curso de formación, inicial o de superación. El permite una apreciación expedita de la metodología practicada por un profesor, haciendo posible organizar la formación desde el debate y reflexión sobre las concepciones metodológicas de los participantes en una perspectiva constructivista de la formación.

Palabras-clave

Enseñanza constructivista; Enseñanza de ciencias; Estrategias de enseñanza; Perfil metodológico

Recebido em março/2015 Aceite para publicação em junho/2016

i Escola Superior de Educação e Comunicação, Universidade do Algarve, Faro, Portugal. 


\section{Anexo 1 - Sequência Pedagógica}

As frases do quadro seguinte traduzem acontecimentos pedagógicos frequentemente presentes no ensino, independentemente da orientação metodológica adotada.

1. Selecione os que estão presentes no início da última sequência de ensino que leccionou.

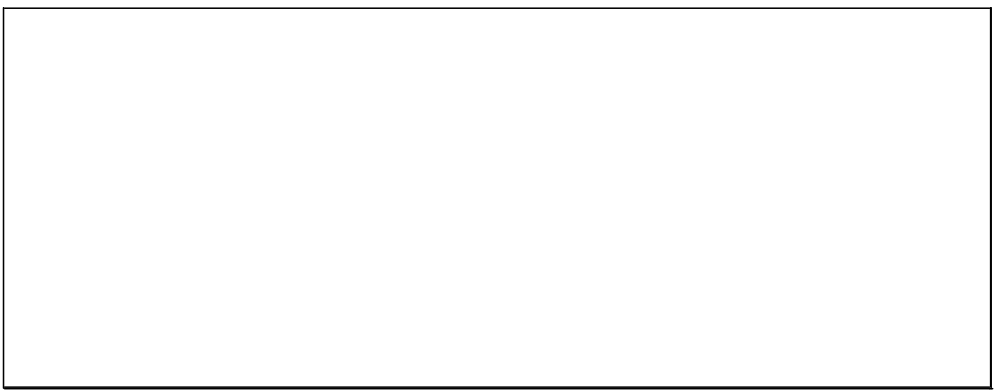

A- Pelo diálogo ou exposição apresentam-se alguns factos ou aspectos relativos ao assunto.

B- Os alunos têm oportunidade de contactar com situações ou acontecimentos relativos ao assunto.

C- Os alunos expuseram pelo diálogo, ou de outro modo, o que entendiam do tema ou assunto.

D- Listaram-se um conjunto de questões ou interesses a partir dos quais se organizou a sequência das aprendizagens.

E- Os conteúdos foram introduzidos numa sequência ditada pela lógica das relações entre si, dum modo muito próximo da estrutura da matéria no livro adotado.

F- Os alunos aprendem pelo recurso a fontes diversificadas de informação.

G- O professor introduziu exemplos e situações da vida quotidiana relativas aos conceitos envolvidos.

2. Indique-os pela ordem em que aparecem na sequência pedagógica.

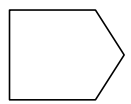

$1^{\circ}$

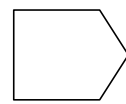

$2^{\circ}$

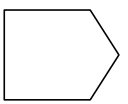

$3^{\circ}$

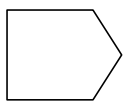

$4^{\circ}$

3. Explicite pelas suas próprias palavras cada uma das escolhas efetuadas (max. 3-4 linhas para cada). 
Anexo 2 - Processos de Pensamento Científico

Nas atividades e tarefas propostas nessa Unidade, tanto no período letivo, como fora dele, os alunos sozinhos ou em grupo, tiveram oportunidade, por eles mesmos de...

\begin{tabular}{|l|l|l|l|l|l|}
\hline \multicolumn{1}{|c|}{ item } & \multicolumn{3}{l}{$\mathrm{N}^{\circ}$ vezes que ocorreu } \\
\hline \multicolumn{1}{|l|}{} & 0 & 1 & 2 & 3 ou + \\
\hline Planeamento & & & & \\
\hline Formular o problema ou questão & & & & \\
\hline Prever o resultado de uma experimentação & & & & \\
\hline Formular a hipótese experimental & & & & \\
\hline Definir o que observar ou como proceder & & & & \\
\hline Delinear uma experimentação & & & \\
\hline
\end{tabular}

\begin{tabular}{|l|l|l|l|l|}
\hline Desempenho & & & & \\
\hline Executar as orientações dadas & & & & \\
\hline Fazer observações e medições & & & & \\
\hline Manipular equipamentos & & & & \\
\hline Registar resultados & & & & \\
\hline Fazer cálculos numéricos & & & & \\
\hline Explicar um procedimento & & & & \\
\hline Trabalhar segundo um plano pessoal & & & \\
\hline
\end{tabular}

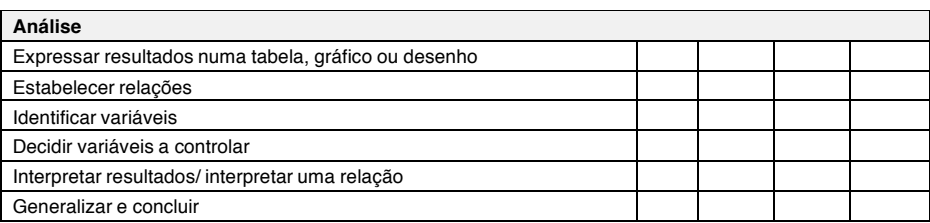

\begin{tabular}{|l|l|l|l|l|}
\hline Aplicação & & & & \\
\hline Prever resultados com base nos resultados anteriores & & & & \\
\hline Explicar acontecimentos com base nos conhecimentos & & & & \\
\hline Aplicar procedimentos & & & & \\
\hline Aplicar procedimentos em novos contextos & & & \\
\hline
\end{tabular}




\section{Anexo 3 - Inquérito sobre como aprendes Ciências da Natureza}

Como aprendeste a última matéria que estudaste?

Para cada um dos aspetos descritos na coluna do lado esquerdo, indica o contributo que teve para o que aprendeste. Em cada um dos aspetos coloca uma cruz $(\mathrm{X})$ no espaço que corresponde ao modo como aprecias o contributo para a tua aprendizagem: Muito, alguma coisa, pouco ou nada.

\begin{tabular}{|l|l|l|l|l|}
\hline Aspecto & muito & $\begin{array}{l}\text { alguma } \\
\text { coisa }\end{array}$ & pouco & nada \\
\hline Explicação feita pelo professor & & & & \\
\hline Diálogo entre os alunos e o professor e os alunos & & & & \\
\hline Experiências feitas por mim e pelos meus colegas & & & & \\
\hline Experiências que vi o professor fazer & & & & \\
\hline Visitas de estudo e outras actividades extra aula & & & & \\
\hline Perguntas que o professor fez & & & & \\
\hline Em conversa com outras pessoas & & & & \\
\hline No livro de ciências & & & & \\
\hline Noutros livros que li & & & & \\
\hline Com fichas de trabalho do professor & & & & \\
\hline Com filmes, fotografias ou slides que vi na aula & & & & \\
\hline Com programas de televisão que vi & & & & \\
\hline Com o trabalho de grupo com os outros colegas & & & & \\
\hline
\end{tabular}

